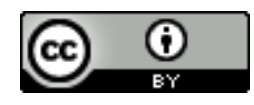

Esta obra está sob o direito de Licença Creative Commons Atribuição 4.0 Internacional.

\title{
A IMPORTÂNCIA DO PROCESSO DE TRATAMENTO DE ÁGUA PARA O SAA E PARA A POPULAÇÃO
}

\author{
Ivis Kally Pereira Patriota ${ }^{1}$ \\ Maria Clara da Rocha dos Santos Silva \\ Nathalia Danielle da Silva ${ }^{3}$ \\ Rafael Bispo Vieira Monteiro ${ }^{4}$ \\ Eduardo Cabral da Silva ${ }^{5}$
}

\begin{abstract}
RESUMO
A expansão desordenada das cidades próximas aos mananciais, aliada à falta de infraestrutura básica para esses novos núcleos habitacionais, favorece a degradação dos mananciais usados para o abastecimento público de água. Sendo assim, a população está mais suscetível às doenças de veiculação hídrica, pois a presença de bactérias em reservatórios é um desafio para a produção de água potável. Independentemente dos tipos de poluentes presentes na água, buscase o aprimoramento das tecnologias tradicionalmente utilizadas no processo de tratamento de água para garantir que as pessoas tenham água potável. Com base no texto supracitado o presente trabalho se propõe a avaliar por meio de uma revisão sistemática integrativa a importância do processo de tratamento de água em sistemas de abastecimento de águas para proporcionar o desenvolvimento socioeconômico e a melhoria da qualidade de vida da população. Analisaram-se os artigos publicados na base de dados da plataforma SCIELO entre os anos de 2015 e 2020, sobre ETA, SAA e população, adotando alguns critérios de inclusão e exclusão. A busca resultou em oito artigos de relevância para o contexto e a problemática proposta, que foram explorados e discutidos. Portanto, é de suma importância que haja fiscalização e o emprego correto das estações de tratamento de água no processo de tratamento de água para o sistema de abastecimento de água.
\end{abstract}

Palavras-chave: Abastecimento de águas. Saúde Pública. Desenvolvimento regional.

\footnotetext{
1 ivis.patriota@gmail.com

2 clara_rochha@outlook.com

3 nathaliadanielledasilva@gmail.com

4 rafaelbispo97@gmail.com

${ }^{5}$ eduardo.csilva@professores.unifavip.edu.br
} 


\section{INTRODUÇÃO}

A superfície terrestre encontra-se coberta aproximadamente por $70 \%$ de água, contudo, menos de $3 \%$ desse volume é de água doce e, a maior parte está em geleiras, restando assim, apenas uma pequena porcentagem facilmente disponível para uso direto (FONTE).

A água encontrada na natureza não é própria para consumo, pois contém impurezas, mesmo quando cai em forma de chuva ou quando se encontra no subsolo, pois a mesma sofre interferências do meio e altera suas características físicas, químicas e microbiológicas.

Sendo assim, para ser considerada própria para consumo, a água, precisa atender aos padrões de potabilidade. Caso haja alguma substância que altere seu padrão (compostos nitrogenados, oxigênio consumido e cloretos), a água é considerada como poluída, e portanto, imprópria para consumo.

Um sistema de Abastecimento de água (SAA) consiste em um conjunto de obras e instalações que englobam a captação, adução, tratamento e distribuição de água potável para atender uma determinada população, beneficiando os indivíduos que a compõem (FONTE).

É fundamental que a água utilizada no abastecimento da população esteja em estado de consumo adequado, de forma a reduzir a incidência de doenças de veiculação hídrica. Os SAAs, são estrutura responsáveis por distribuírem água aos consumidores de acordo com o padrão de potabilidade exigido pela Portaria de Consolidação $\mathrm{N}^{\circ} 5$ do Ministério da Saúde. A Estações de Tratamento de Água - ETA é a unidade do SAA responsável pela adequação da água bruta ao padrão de potabilidade.

Nos grandes centros urbanos, devido à baixa qualidade dos mananciais, ocasionada pelo lançamento de efluentes industriais e esgotos urbanos, é necessário realizar tratamentos mais complexos antes de distribuir água à população. $\mathrm{O}$ processo de tratamento da água inclui uma série de processos físicos e químicos aplicados na mesma para que esteja em condições de consumo (FONTE).

A falta ou ineficiência do serviço de tratamento de água pode agravar a saúde e a qualidade de vida das pessoas. Partindo desse pressuposto, este artigo tem como objetivo analisar os processos e as etapas pelas quais passa a água bruta até chegar ao padrão de potabilidade para consumo humano.

\section{MÉTODOLOGIA}

A metodologia adotada no presente trabalho trata-se de uma revisão sistemática integrativa que teve como base de buscas a base da SCIELO. Os descritores assinalados no Quadro 1 conectados pelo operador booleano "And" foram utilizados para otimizar as buscas por artigos dentro da temática central.

Para o escopo deste estudo, consideraram-se como critérios de inclusão: Artigos publicados entre 2015 e 2021, que respondiam à pergunta norteadora $\mathrm{e}$ atendiam a temática estabelecida pelos descritores. Foram excluídos artigos que não contemplam a temática. Para os artigos selecionados para a discussão da presente temática, criou-se um fichamento protocolar contemplando: títulos, ano, autor, palavras chave e tipo de pesquisa (Quadro 3). 


\section{QUADRO 1}

DETALHAMENTO DAS ETAPAS DA REVISÃO SISTEMÁTICA INTEGRATIVA.

\begin{tabular}{|c|c|c|c|}
\hline ETAPA & $\begin{array}{l}\text { TÓPICOS DE } \\
\text { CADA ETAPA }\end{array}$ & \multicolumn{2}{|c|}{ DETALHAMENTO DE CADA TÓPICO } \\
\hline \multirow{14}{*}{$1^{\mathrm{a}}$} & Tema & \multicolumn{2}{|r|}{ Tratamento de água para SAA } \\
\hline & Pergunta norteadora & \multicolumn{2}{|c|}{$\begin{array}{l}\text { Qual a importância do processo de tratamento de } \\
\text { água para o SAA e para a população? }\end{array}$} \\
\hline & Objetivo geral & \multicolumn{2}{|c|}{$\begin{array}{c}\text { Analisar o processo e as etapas pelas quais passa a } \\
\text { água bruta até chegar à possibilidade de consumo } \\
\text { humano. }\end{array}$} \\
\hline & Estratégias de busca & \multicolumn{2}{|c|}{$\begin{array}{l}\text { 1. Cruzamento de descritores por meio do operador } \\
\text { booleano AND; } \\
\text { 2. Uso de aspas nos politermos (descritor com mais } \\
\text { de um termo) para que a varredura de artigos } \\
\text { científicos contemplasse o termo exato; } \\
\text { 3. Uso de descritores estruturados (codificação) no } \\
\text { DECS ou MESH; } \\
\text { 4. Uso de metadados (filtros) nas bibliotecas } \\
\text { virtuais; }\end{array}$} \\
\hline & \multirow{3}{*}{$\begin{array}{c}\text { Bancos de } \\
\text { terminologias }\end{array}$} & Banco & Link \\
\hline & & DeSC & http://decs.bvs.br/ \\
\hline & & $\mathrm{MeSH}$ & https://www.ncbi.nlm.nih.gov/mesh \\
\hline & \multirow{4}{*}{$\begin{array}{l}\text { Descritores livres e } \\
\text { estruturados }\end{array}$} & $\begin{array}{c}\text { Descrito } \\
\mathbf{r}\end{array}$ & DeCS (Registro) \\
\hline & & ETA & 51772 \\
\hline & & SAA & 15285 \\
\hline & & $\begin{array}{c}\text { Populaçã } \\
\text { o }\end{array}$ & 13305 \\
\hline & String de busca & & $\begin{array}{c}\text { SAA and ETA } \\
\text { ETA and população } \\
\text { SAA and população }\end{array}$ \\
\hline & & Bibliote & Link \\
\hline & Bibliotecas virtuais & Scielo & https://scielo.org/ \\
\hline \multirow{3}{*}{$2^{\mathrm{a}}$} & $\begin{array}{c}\text { Período de coleta dos } \\
\text { dados }\end{array}$ & \multicolumn{2}{|r|}{ 26/04/2021 a 02/05/2021 } \\
\hline & Critérios de inclusão & \multicolumn{2}{|r|}{$\begin{array}{l}\text { 12. Artigos (artigo científicos e free). } \\
\text { 13. Publicação (2015-2021). }\end{array}$} \\
\hline & Critérios de exclusão & \multicolumn{2}{|c|}{ 5. Artigos que não contemplam a temática } \\
\hline $3^{\mathrm{a}}$ & $\begin{array}{l}\text { Número de trabalhos } \\
\text { selecionados para } \\
\text { revisão sistemática } \\
\text { integrativa a partir da } \\
\text { leitura dos agentes } \\
\text { indexadores das } \\
\text { publicações (tema, } \\
\text { descrição, ementa). }\end{array}$ & \multicolumn{2}{|r|}{08} \\
\hline
\end{tabular}




\begin{tabular}{|c|c|c|}
\hline $4^{\mathrm{a}}$ & $\begin{array}{c}\text { Categorias obtidas } \\
\text { com a análise dos } \\
\text { documentos } \\
\text { investigados online } \\
\text { gratuitos e de livre } \\
\text { acesso }\end{array}$ & $\begin{array}{c}3 \text { categorias: } \\
\text { Saúde e sociedade }\end{array}$ \\
\hline $5^{\mathrm{a}}$ & $\begin{array}{c}\text { Análise, interpretação } \\
\text { e discussão dos } \\
\text { resultados }\end{array}$ & $\begin{array}{c}\text { Engenharia Sanitária e ambiental } \\
\text { Processos de uma ETA }\end{array}$ \\
\hline \multirow{2}{*}{$6^{\mathrm{a}}$} & $\begin{array}{c}\text { Apresentação da } \\
\text { revisão em formato de } \\
\text { artigo, o qual } \\
\text { contemple propostas } \\
\text { para estudos futuros }\end{array}$ & Ver em "Resultados e Discussão" \\
\hline
\end{tabular}

Fonte: elaborada pelos autores.

\section{RESULTADOS}

O detalhamento sobre as strings de busca utilizadas na base de dados da plataforma de periódicos SCIELO e os respectivos dados quantitativos sobre os resultados dos artigos nas buscas estão dispostos no Quadro 2. Dentro dessa perspectiva, a string com maior quantidade de artigos encontrados dentro da temática foi "SAA And ETA", com o total de 594 trabalhos, sendo que, desses apenas 3 selecionados para compor os resultados e discussões.

\section{QUADRO 2}

\section{CORRESPONDE AO TOTAL DE DOCUMENTOS DISPONÍVEIS NA PLATAFORMA SCIELO OBTIDOS POR STRING DE BUSCA.}

\begin{tabular}{|c|c|c|c|c|}
\hline $\begin{array}{c}\text { String de } \\
\text { busca }\end{array}$ & $\begin{array}{c}\text { Bases de } \\
\text { dados }\end{array}$ & $\begin{array}{c}\text { Total de } \\
\text { publicações } \\
\text { sem o filtro }\end{array}$ & $\begin{array}{c}\text { Publicações } \\
\text { disponíveis } \\
\text { após aplicar os } \\
\text { filtros }\end{array}$ & $\begin{array}{c}\text { Publicações } \\
\text { aproveitadas na } \\
\text { Revisão Sistemática } \\
\text { Integrativa }\end{array}$ \\
\hline $\begin{array}{c}\text { SAA and } \\
\text { ETA }\end{array}$ & SCIELO & 594 & 161 & 3 \\
\hline $\begin{array}{c}\text { ETA and } \\
\text { população }\end{array}$ & SCIELO & 423 & 201 & 3 \\
\hline $\begin{array}{c}\text { SAA and } \\
\text { população }\end{array}$ & SCIELO & 99 & 42 & 2 \\
\hline
\end{tabular}

Fonte: elaborada pelos autores.

O detalhamento dos trabalhos selecionados para a discussão da presente temática está apresentado no Quadro 3.
Foram selecionados 8 artigos publicados entre os anos de 2015 e 2021. 
QUADRO 3

DESCRIÇÃO DOS DOCUMENTOS (ARTIGOS) DE ACORDO COM OS CRITÉRIOS DE INCLUSÃO.

\begin{tabular}{|c|c|c|c|c|c|}
\hline $\mathbf{N}^{\mathbf{o}}$ & $\begin{array}{c}\text { Autor } \\
\text { (a) }\end{array}$ & Tema & $\begin{array}{c}\text { Link da } \\
\text { Publicação }\end{array}$ & $\begin{array}{c}\text { Data da } \\
\text { publicação }\end{array}$ & Conclusão \\
\hline 01 & $\begin{array}{c}\text { Nathalie } \\
\text { Cruz }\end{array}$ & $\begin{array}{l}\text { Saúde pública e } \\
\text { inovações } \\
\text { tecnológicas para } \\
\text { abastecimento } \\
\text { público }\end{array}$ & $\begin{array}{c}\text { https://doi.org/ } \\
10.1590 / \mathrm{s} 0104 \\
- \\
129020201808 \\
24\end{array}$ & 03.02 .2020 & $\begin{array}{l}\text { A escassez, a distância e a poluição de mananciais tornam pouco viável a } \\
\text { prática do reuso potável indireto. Os sistemas de tratamento tradicionais, tanto } \\
\text { para águas residuárias como para água potável, já não são suficientes para } \\
\text { promover uma água segura à população. Por isso, é necessário aprimorar as } \\
\text { tecnologias capazes de remover contaminantes orgânicos, inorgânicos e } \\
\text { organismos patogênicos que os processos comumente utilizados não são. Em } \\
\text { paralelo, a fim de atender à realidade dos mananciais, é essencial aprimorar } \\
\text { instrumentos legais para monitorar os processos utilizados. [...] }\end{array}$ \\
\hline 02 & $\begin{array}{l}\text { Rívea } \\
\text { Medri } \\
\text { Borges }\end{array}$ & $\begin{array}{l}\text { Uso de filtros de } \\
\text { carvão ativado } \\
\text { granular } \\
\text { associado a } \\
\text { microrganismos } \\
\text { para remoção de } \\
\text { fármacos no } \\
\text { tratamento de } \\
\text { água de } \\
\text { abastecimento }\end{array}$ & $\begin{array}{c}\text { https://doi.org/ } \\
\text { 10.1590/s1413 } \\
- \\
415220161187 \\
87\end{array}$ & 05.09 .2016 & $\begin{array}{l}\text { O uso de linhagens específicas de microrganismos capazes de metabolizar } \\
\text { eficientemente esses fármacos pode vir a representar uma proposta para a } \\
\text { ativação biológica de leitos de filtros de carvão na busca por desenvolver uma } \\
\text { configuração de sistema que contribua para o aumento da eficiência e redução } \\
\text { do custo do tratamento de água na remoção desses compostos.O uso de filtros } \\
\text { biológicos de carvão pode representar uma técnica promissora para a remoção } \\
\text { de fármacos e outros compostos recalcitrantes presentes nos mananciais de } \\
\text { abastecimento público. }\end{array}$ \\
\hline 03 & $\begin{array}{c}\text { Henrique } \\
\text { Gamon } \\
\text { Sonobe }\end{array}$ & $\begin{array}{l}\text { Avaliação } \\
\text { espacial e } \\
\text { temporal de } \\
\text { aspectos } \\
\text { sanitários de } \\
\text { reservatórios com } \\
\text { captação de água } \\
\text { para } \\
\text { abastecimento em }\end{array}$ & $\begin{array}{c}\text { https://doi.org/ } \\
\text { 10.1590/s1413 } \\
- \\
415220191933 \\
51\end{array}$ & 25.11.2019 & $\begin{array}{l}\text { Por fim, esta pesquisa permitiu concluir que ainda existe, no Brasil, uma falta } \\
\text { de integração entre as diferentes leis e resoluções relativas à qualidade das } \\
\text { águas, por exemplo, em relação à uniformização das frequências de } \\
\text { amostragem e monitoramento. Além disso, a presente análise mostrou que } \\
\text { alguns dos reservatórios estudados, a despeito de serem utilizados para } \\
\text { abastecimento público, possuem indicadores de contaminação e aporte } \\
\text { significativo de matéria orgânica e outros poluentes. Ressalta-se, assim, a } \\
\text { importância de investimentos na coleta e no tratamento de esgotos sanitários } \\
\text { até níveis secundário e terciário para evitar o aporte excessivo de matéria }\end{array}$ \\
\hline
\end{tabular}




\begin{tabular}{|c|c|c|c|c|c|}
\hline & & $\begin{array}{l}\text { SP com ênfase em } \\
\text { cianobactérias e } \\
\text { cianotoxinas }\end{array}$ & & & $\begin{array}{l}\text { orgânica e nutrientes aos mananciais. Recomenda-se ainda que as estações de } \\
\text { tratamento que operam com as águas dos reservatórios Cascata possuam } \\
\text { etapas avançadas para eventual necessidade de remoção de cianotoxinas. }\end{array}$ \\
\hline 04 & $\begin{array}{l}\text { Edumar } \\
\text { Ramos } \\
\text { Cabral } \\
\text { Coelho }\end{array}$ & $\begin{array}{l}\text { Desenvolvimento } \\
\text { e validação de } \\
\text { método analítico } \\
\text { para análise de } \\
\text { 2,4-D, 2,4-DCP e } \\
\text { 2,4,5-T para } \\
\text { monitoramento } \\
\text { em água de } \\
\text { abastecimento } \\
\text { público. }\end{array}$ & $\begin{array}{c}\text { https://doi.org/ } \\
10.1590 / \text { s1413 } \\
- \\
415220181615 \\
36\end{array}$ & 12.07 .2017 & $\begin{array}{l}\text { O método de análise de agrotóxicos em água utilizando EFS e CLAEDAD } \\
\text { demonstrou seletividade, linearidade ( } \mathrm{r} \geq 0,997) \text {, precisão (CV } \leq 12 \%) \text { e exatidão } \\
\geq 85 \% \text { para separar e quantificar simultaneamente os compostos } 2,4-\mathrm{D}, 2,4- \\
\mathrm{DCP} \text { e } 2,4,5-\mathrm{T} \text { em água filtrada e água de manancial superficial. Os valores } \\
\text { de LD entre } 0,17 \text { e } 0,51 \mu \mathrm{g} \text {. L- } 1 \text { e de LQ de } 1,0 \mu \mathrm{g} \text {. L-1 atendem aos limites } \\
\text { estabelecidos pela Portaria MS n } \text { n }^{\circ} 2.914 / 2011 \text {. Portanto, o método apresentado } \\
\text { pode ser utilizado para a detecção e a quantificação concomitante de } 2,4-\mathrm{D} \text {, } \\
\text { 2,4-DCP e } 2,4,5-\mathrm{T} \text { em águas de abastecimento público e no controle e no } \\
\text { monitoramento ambiental, atendendo os limites estabelecidos nas legislações } \\
\text { brasileiras. }\end{array}$ \\
\hline 05 & $\begin{array}{c}\text { Paulo } \\
\text { Henrique } \\
\text { Mazieiro } \\
\text { Pohlman } \\
\text { n }\end{array}$ & $\begin{array}{c}\text { Tratamento de } \\
\text { água para } \\
\text { abastecimento } \\
\text { humano: } \\
\text { contribuições da } \\
\text { metodologia Seis } \\
\text { Sigma. }\end{array}$ & $\begin{array}{c}\text { https://doi.org/ } \\
10.1590 / S 1413 \\
- \\
415220150200 \\
00097976\end{array}$ & 04.03.2015 & $\begin{array}{l}\text { [...] A princípio, o programa Seis Sigma mostra-se uma importante ferramenta } \\
\text { para a melhoria contínua e para a padronização dos processos envolvidos na } \\
\text { ETA, promovendo a visibilidade das oportunidades de defeito e } \\
\text { estabelecendo, por meio disso, padrões de excelência de desempenho. } \\
\text { Recomenda-se a realização de estudos mais aprofundados para a verificação } \\
\text { prática desta simulação e solução das dificuldades encontradas. Inúmeros são } \\
\text { os benefícios para a sociedade, para a administração das ETAs e para os } \\
\text { profissionais envolvidos no setor, como: redução da variabilidade e das não } \\
\text { conformidades, redução dos desperdícios com recursos, melhoria contínua, } \\
\text { desenvolvimento de uma metodologia sistemática para a resolução de } \\
\text { problemas e aumento da confiabilidade do processo. [...] }\end{array}$ \\
\hline 06 & $\begin{array}{l}\text { Katia } \\
\text { Sakiham } \\
\text { a Ventura }\end{array}$ & $\begin{array}{c}\text { Plano de } \\
\text { segurança da água } \\
\text { implementado na } \\
\text { estação de } \\
\text { tratamento de } \\
\text { água de Guaraú, } \\
\text { em São Paulo. }\end{array}$ & $\begin{array}{c}\text { https://doi.org/ } \\
10.1590 / s 1413 \\
- \\
415220191698 \\
81\end{array}$ & 18.10.2017 & $\begin{array}{l}\text { O PSA é instrumento preventivo útil ao planejamento do abastecimento } \\
\text { hídrico e visa à preservação do recurso, em quantidade e qualidade, para } \\
\text { distintos usos e especificidades na bacia hidrográfica. Dessa forma, } \\
\text { recomenda-se que seja elaborado e implantado com base nas diretrizes dos } \\
\text { planos de bacia. Os planos de bacia hidrográfica indicam o cenário do } \\
\text { saneamento e as ações que devem ser priorizadas para atingir a } \\
\text { universalização na bacia como um todo. Nesse sentido, o PSA contribui com } \\
\text { as diretrizes dos referidos planos, pois apresenta a previsão de riscos, a }\end{array}$ \\
\hline
\end{tabular}




\begin{tabular}{|c|c|c|c|c|c|}
\hline & & & & & $\begin{array}{l}\text { probabilidade de ocorrência e suas consequências, apontando o nível de } \\
\text { comprometimento para o abastecimento de água para consumo humano. [...] }\end{array}$ \\
\hline 07 & $\begin{array}{c}\text { Keila } \\
\text { Castro } \\
\text { Oliveira }\end{array}$ & $\begin{array}{l}\text { Esporos de } \\
\text { bactérias aeróbias } \\
\text { são bons } \\
\text { indicadores da } \\
\text { eficiência do } \\
\text { tratamento de } \\
\text { água? Um estudo } \\
\text { exploratório. }\end{array}$ & $\begin{array}{l}\text { https://doi.org/ } \\
10.1590 / s 1413 \\
- \\
415220181515 \\
90\end{array}$ & 25.07.2017 & $\begin{array}{c}\text { EBA foram detectados em números elevados na água bruta, e removidos de } \\
\text { forma consistente ao longo das etapas do tratamento, mas permaneceram } \\
\text { presentes nos efluentes de cada uma dessas etapas. Isso possibilitou a } \\
\text { quantificação de decaimento ao longo do tratamento e, por conseguinte, } \\
\text { demonstra o potencial de uso de EBA como indicadores da eficiência do } \\
\text { tratamento da água. [...] }\end{array}$ \\
\hline 08 & $\begin{array}{l}\text { Ruth } \\
\text { Silveira } \\
\text { do } \\
\text { Nascime } \\
\text { nto }\end{array}$ & $\begin{array}{l}\text { Simulação de } \\
\text { alterações numa } \\
\text { ETA } \\
\text { convencional de } \\
\text { porte médio para } \\
\text { a produção de } \\
\text { água segura. }\end{array}$ & $\begin{array}{c}\text { https://doi.org/ } \\
\text { 10.21168/rbrh. } \\
\text { v21n2.p439- } \\
450\end{array}$ & 22.01.2016 & $\begin{array}{c}\text { A utilização do simulador EPANET e a avaliação de risco da qualidade da } \\
\text { água são ferramentas úteis na gestão do desempenho de SAA, especialmente } \\
\text { num contexto de exigência de adoção do Plano de Segurança da Água, por } \\
\text { parte de agências e autoridades de saúde. A aplicação dessas ferramentas } \\
\text { representa uma significativa contribuição para o controle e a vigilância da } \\
\text { qualidade da água por possibilitar a compreensão dos impactos positivos } \\
\text { causados na qualidade da água por alterações propostas no âmbito da ETA. } \\
{[\ldots . . .]}\end{array}$ \\
\hline
\end{tabular}

Fonte: elaborada pelos autores. 
Após o preenchimento do Quadro 3, utilizam-se as conclusões dos artigos para a realização da análise por meio da frequência de palavras, que originou a nuvem de palavras (Figura 1). Para a criação da nuvem foi utilizada a Plataforma online WordArt. Esta ferramenta agrupa e organiza graficamente as palavras-chave evidenciando-as as mais frequentes e que, portanto, deu subsídio para confecção das categorias de discussões.

Por meio da Figura 1, foi possível observar que as palavras em evidência na nuvem pertencem às categorias desenvolvidas a partir da análise de conteúdo de Bardin. Todas as categorias derivam da sua frequência (Tabela 1), que diz respeito ao seu quadro referencial. Em consonância ao objetivo deste trabalho, optou-se por descrever as palavras que apresentaram frequência total no texto e, a partir de seus sentidos nos campos textuais, tinham maior relevância para as representações sociais sobre a importância do processo de tratamento de água para o SAA e para a população, como apresentado na Figura 1.

\section{Figura 1 - Nuvem de palavras}

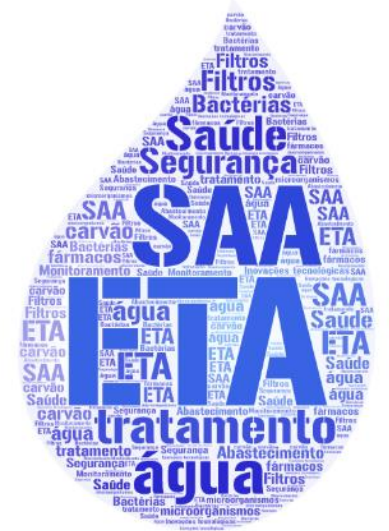

Fonte: elaborada pelos autores.

TABELA 1.

FREQUÊNCIA DAS PALAVRAS PRESENTES NOS TEXTOS PUBLICADOS NA PLATAFORMA SCIELO.

\begin{tabular}{c|c|c}
\hline PALAVRAS & FREQUÊNCIA & CATEGORIAS \\
\hline ETA & 43 & 3 \\
\hline SAA & 39 & 3 \\
\hline Tratamento & 37 & 3 \\
\hline Água & 35 & 2 \\
\hline Segurança & 32 & 3 \\
\hline Saúde & 30 & 3 \\
\hline Abastecimento & 29 & 1 \\
\hline Bactérias & 25 & 3 \\
\hline Microrganismos & 23 & 3 \\
\hline Monitoramento & 22 & 2 \\
\hline Inovação & 10 & 1 \\
\hline Tecnológica & & 1 \\
\hline Filtros & 9 & 1 \\
\hline Fármacos & 5 &
\end{tabular}

Fonte: elaborada pelos autores. 


\section{DISCUSSÃO}

As categorias de discussão abaixo, oriundas da análise das frequências das palavras (Tabela 1) e da evidência dessas diante da nuvem (Figura 1), assim como, da análise técnica das temáticas abordadas nos artigos selecionados e dispostos no Quadro 3, deram subsídio para discussões pertinentes a temática central do artigo. Abaixo seguem as 3 (três) categorias elaboradas.

\section{Saúde e sociedade}

A análise obtida sobre os artigos pesquisados foi que o reuso potável indireto é um risco para a população, pois favorece o surgimento de doenças. Para solucionar este problema e promover saúde para a população, faz-se necessário um tratamento avançado dos efluentes domésticos seguido por tratamento convencional ou avançado em ETA, levando em conta que "O reuso potável direto é seguro por contar com técnicas de certificação da qualidade hídrica que permitem produzir água a partir de esgotos domésticos, respeitando critérios econômicos e de saúde pública." (CRUZ E MIERZWA, 2020).

Logo, as medidas necessárias para promoção da saúde e prevenção de contaminação das águas de abastecimento são, criar barreiras de proteção à contaminação nos mananciais de captação de água, garantindo a coleta e tratamento de esgotos, uso e ocupação dos solos de forma ordenada e distanciamento dos dejetos dos mananciais utilizados para o abastecimento, segundo a recomendação da Organização Mundial de Saúde (OMS, 2017).

\section{ENGENHARIA SANITÁRIA E AMBIENTAL}

Através da implantação de sistemas de engenharias, há vários tratamentos avançados numa ETA. Como por exemplo a utilização de membranas para remoção de substâncias por processos de tratamento de água, onde "são responsáveis pela remoção de poluentes químicos tradicionais e emergentes, mesmo os de baixa massa molecular, como os disruptores endócrinos, e de organismos patogênicos de dimensões muito pequenas, por exemplo, os oocistos de Cryptosporidium spp." (CRUZ E MIERZWA, 2020). Também utiliza o carvão ativado biológico, que ocorre "pela ação de oxidante forte aplicado na entrada da unidade filtrante.

Dessa maneira, são removidos materiais orgânicos (geralmente biodegradáveis), não orgânicos (compostos estáveis e de difícil degradação) e organismos patogênicos contidos em águas superficiais ou subterrâneas." (CRUZ E MIERZWA, 2020). Além do carvão ativado biológico houve estudos sobre o uso de filtros granulares de carvão ativado relacionado a microrganismos para remover fármacos da água potável. Os estudos não se limitam só no tratamento avançado de uma ETA, mas também acerca de todo o processo do sistema de abastecimento de água, como o avaliação espaço-temporal de aspectos sanitários dos reservatórios de água, onde surgem métodos analíticos e contribuições da metodologia de Seis Sigma. Foi criado também o Plano de Segurança das Águas, que representa uma estratégia para prever os perigos que podem comprometer a qualidade da água potável e monitorar os riscos.

Para Ventura, Vaz Filho e Nascimento (2019): "Para implantar o PSA 
em estação de tratamento de água (ETA), é necessário conhecer as práticas operacionais do abastecimento do sistema como um todo, especialmente a etapa de tratamento, para que as variáveis de controle, de identificação de perigos e de caracterização de riscos sejam eficazes. Dessa forma, é possível reduzir ou eliminar a presença de determinadas substâncias, elementos químicos e micro-organismos que possam estar presentes no corpo hídrico e interferir no controle dos aspectos sanitários, estéticos e econômicos."

\section{PROCESSOS DE UMA ETA}

Numa Estação de Tratamento de Água convencional, primeiro ocorre a chegada de água bruta na ETA, onde a água é proveniente de manancial superficial ou subterrâneo, o local da chegada da água se chama caixa de reunião. Logo em seguida, a água vai para a etapa de mistura rápida, que é onde adiciona o coagulante (aplicação do produto químico), - que no caso, pose ser utilizado o sulfato de alumínio liquido -, "este produto faz com que as partículas de impurezas grudem umas nas outras formandos flocos que são facilmente removidos" (COMPESA, 2012).

\section{CONCLUSÃO}

A escassez, a distância e a poluição de recursos hídricos, tornam quase impossível a prática do reuso indireto da água. Os sistemas tradicionais de tratamento de águas residuais e de água potável não são mais suficientes para fornecer água potável às pessoas. Portanto, é necessário aprimorar a tecnologia que pode remover poluentes orgânicos e inorgânicos e patógenos que não podem ser removidos por métodos comumente usados. Ao mesmo tempo, para atender à realidade dos recursos hídricos, é
$\mathrm{Na}$ etapa de floculação faz-se necessários de movimentos lentos para que os flocos possam se agrupar sem quebrar. É realizado por floculação mecânica, considerando que os agitadores tenham flexibilidade de aumentar ou diminuir o movimento da água. "Da floculação a água segue para a decantação, que como os flocos de sujeiras são mais pesados, eles descem e ficam no fundo do decantador. Depois de decantada a água precisa ser filtrada." (COMPESA, 2012). Na filtração a água atravessa uma camada de areia onde ocorre o polimento, onde ocorre a remoção do material mais fino que não conseguiu ser agregado no decantador, para ser sedimentado.

Logo depois, a água é encaminhada para o Reservatório de Água Tratada e Tanques de Contato, onde é feito a cloração que garante a desinfecção da água. A água é testada em certos períodos para garantir sua qualidade, e os testes são realizados no laboratório que existe na própria ETA. "Depois de tratada e analisada, pode ser dito que a água é potável e que pode ser consumida sem causar qualquer risco à saúde.” (COMPESA, 2012)

necessário aprimorar os instrumentos legais de monitoramento dos processos utilizados.

Este estudo mostra que através da implantação de sistemas de engenharia, o saneamento e o tratamento da água são uma medida de promoção da saúde, além de uma medida preventiva. Múltiplas barreiras de poluição podem ser estabelecidas para garantir a segurança da água por meio de nascentes protegidas e coleta de esgoto.

Por fim identificou-se que é necessária a atuação de políticas públicas que busquem expandir os serviços de saneamento e de tratamento de água, 
essencialmente para as localidades com situações mais precárias, para assim garantir o uso de água adequada para o

\section{REFERÊNCIAS}

BORGES, Rívea Medri. Et. al. Uso de filtros de carvão ativado granular associado a microrganismos para remoção de fármacos no tratamento de água de abastecimento. Disponível em: $<$ https://www.scielo.br/scielo.php?script=s ci_arttext\&pid=S1413$41522016000400709 \& \operatorname{lng}=p t \& \operatorname{lng}=p t>$. Acesso em: 26/04/2021.

Coelho, Edumar Ramos Cabral. Et. al. Desenvolvimento e validação de método analítico para análise de 2,4-D, 2,4-DCP e 2,4,5-T para monitoramento em água de abastecimento público. Disponível em: $<$ https://www.scielo.br/scielo.php?script=s ci_arttext\&pid=S1413-

$41522018000601043 \&$ tlng $=p t>$. Acesso em: 28/04/2021.

CRUZ, Nathalie. MIERZWA, José Carlos. Saúde pública e inovações tecnológicas para abastecimento público. Disponível em:<https://www.scielo.br/scielo.php?scrip $\mathrm{t}=$ sci_arttext\&pid=S0104$12902020000100301 \&$ tlng=pt $>$. Acesso em: 27/04/2021.

NASCIMENTO, Ruth Silveira. Et. al. Simulação de alterações numa ETA convencional de porte médio para a produção de água segura. Disponível em: <https://www.abrhidro.org.br/SGCv3/publi cacao.php?PUB=1\&ID=190\&SUMARIO= 5197>. Acesso em: 02/05/2021. consumo da população a fim de evitar a disseminação de doenças de veiculação hídrica.

OLIVEIRA, Keila Castro. Et. al. Esporos de bactérias aeróbias são bons indicadores da eficiência do tratamento de água? Um estudo exploratório. Disponível em:

$<$ https://www.scielo.br/scielo.php?script=s ci_arttext\&pid=S1413$41522018000601103 \& t \operatorname{lng}=p t>$. Acesso em: 02/05/2021.

POHLMANN, Paulo Henrique Mazieiro. Et. al. Tratamento de água para abastecimento humano: contribuições da metodologia Seis Sigma. Disponível em: $<$ https://www.scielo.br/scielo.php?script=s ci_arttext\&pid=S1413$41522015000300485 \& \operatorname{lng}=p t \& t \operatorname{lng}=p t>$. Acesso em: 29/04/2021.

SONOBE, Henrique Gamon. Et. al. Avaliação espacial e temporal de aspectos sanitários de reservatórios com captação de água para abastecimento em SP com ênfase em cianobactérias e cianotoxinas. Disponível em:

$<$ https://www.scielo.br/scielo.php?script=s ci_arttext\&pid=S141341522019000500909\&tlng=pt $>$. Acesso em: 27/04/2021.

VENTURA, Katia Sakihama. Et. al. Plano de segurança da água implementado na estação de tratamento de água de Guaraú, em São Paulo. Disponível em: $<$ https://www.scielo.br/scielo.php?script=s ci_arttext\&pid=S141341522019000100109\&tlng=pt $>$. Acesso em: 30/04/2021. 